\title{
Influenza vaccine effectiveness against laboratory- confirmed influenza in hospitalised adults aged 60 years or older, Valencia Region, Spain, 2017/18 influenza
}

\section{season}

Ainara Mira-Iglesias' ${ }^{1}$ F Xavier López-Labrador ${ }^{1,2}$, Víctor Baselga-Moreno1, Miguel Tortajada-Girbés ${ }^{3}$, Juan Mollar-Maseres ${ }^{4}$, Mario Carballido-Fernández ${ }^{5,6}$, Germán Schwarz-Chavarri ${ }^{7}$, Joan Puig-Barberà ${ }^{1,8}$, Javier Díez-Domingo ${ }^{1}$, on behalf of the Valencia Hospital Network for the Study of Influenza and Respiratory Viruses Disease ${ }^{9}$

1. Fundación para el Fomento de la Investigación Sanitaria y Biomédica de la Comunitat Valenciana (FISABIO-Public Health), Valencia, Spain

2. Consorcio de Investigación Biomédica de Epidemiología y Salud Pública (CIBERESP), Instituto de Salud Carlos III, Madrid, Spain

3. Hospital Doctor Peset, Valencia, Spain

4. Hospital Universitario y Politécnico La Fe, Valencia, Spain

5. Hospital General Universitario de Castellón, Castellón, Spain

6. Universidad CEU Cardenal Herrera, Castellón, Spain

7. Hospital General de Alicante, Alicante, Spain

8. Centro de Salud Pública de Castellón, Castellón, Spain

9. The Network members are acknowledged at the end of the article

Correspondence: Javier Díez-Domingo (jdiezdomingo@gmail.com)

Introduction: Influenza immunisation is recommended for elderly people each season. The influenza vaccine effectiveness (IVE) varies annually due to influenza viruses evolving and the vaccine composition. Aim: To estimate, in inpatients $\geq 60$ years old, the $2017 / 18$ trivalent IVE, overall, by vaccine type and by strain. The impact of vaccination in any of the two previous seasons (2016/17 and 2015/16) on current (2017/18) IVE was also explored. Methods: This was a multicentre prospective observational study within the Valencia Hospital Surveillance Network for the Study of Influenza and Respiratory Viruses Disease (VAHNSI, Spain). The test-negative design was applied taking laboratoryconfirmed influenza as outcome and vaccination status as main exposure. Information about potential confounders was obtained from clinical registries and/or by interviewing patients; vaccine information was only ascertained by registries. Results: Overall, $2017 / 18$ IVE was $9.9 \%$ (95\% Cl: -15.5 to $29.6 \%$ ), and specifically, $48.3 \%$ (95\% Cl: $13.5 \%$ to $69.1 \%),-29.9 \%$ (95\% Cl: $-79.1 \%$ to $5.8 \%$ ) and $25.7 \%$ (95\% Cl: $-8.8 \%$ to $49.3 \%)$ against $A\left(\mathrm{H}_{1} \mathrm{~N}_{1}\right)$ pdmog, $A\left(\mathrm{H}_{3} \mathrm{~N}_{2}\right)$ and $B /$ Yamagata lineage, respectively. For the adjuvanted and non-adjuvanted vaccines, overall IVE was $10.0 \%$ (95\% Cl: $-24.4 \%$ to $34.9 \%$ ) and $7.8 \%$ (95\% Cl: $-23.1 \%$ to $31.0 \%)$ respectively. Prior vaccination significantly protected against influenza B/Yamagata lineage (IVE:
$50.2 \% ; 95 \% \mathrm{Cl}: 2.3 \%$ to $74.6 \%$ ) in patients not vaccinated in the current season. For those repeatedly vaccinated against influenza $A\left(\mathrm{H}_{1} \mathrm{~N}_{1}\right)$ pdmo9, IVE was $46.4 \%$ (95\% Cl: $6.8 \%$ to $69.2 \%$ ). Conclusion: Our data revealed low vaccine effectiveness against influenza in hospitalised patients $\geq 60$ years old in $2017 / 18$. Prior vaccination protected against influenza $A\left(\mathrm{H}_{1} \mathrm{~N}_{1}\right) p d m o 9$ and B/Yamagata-lineage.

\section{Introduction}

The World Health Organization (WHO) establishes that vaccination is the most effective way to prevent infection and severe outcomes caused by influenza viruses. Influenza vaccination is widely recommended for preventing seasonal influenza [1], especially for the elderly ( $\geq 65$ years old) as they represent around $90 \%$ of all influenza-related deaths $[2,3]$.

Influenza vaccines need to be reformulated each season due to the constant evolution of influenza viruses as well as the circulation of different influenza virus types from one season to another [4]. Health authorities decide on the vaccine composition for an upcoming season before the end of the previous season based on the information provided by the WHO Global Influenza Surveillance and Response System [5]. 


\section{FIGURE 1}

Selection process and influenza status of hospitalised patients $\geq 60$ years old for the influenza vaccine effectiveness study, Valencia Hospital Network for the Study of Influenza (VAHNSI), Spain, 2017/18 influenza season ( $n=4,858$ eligible patients)

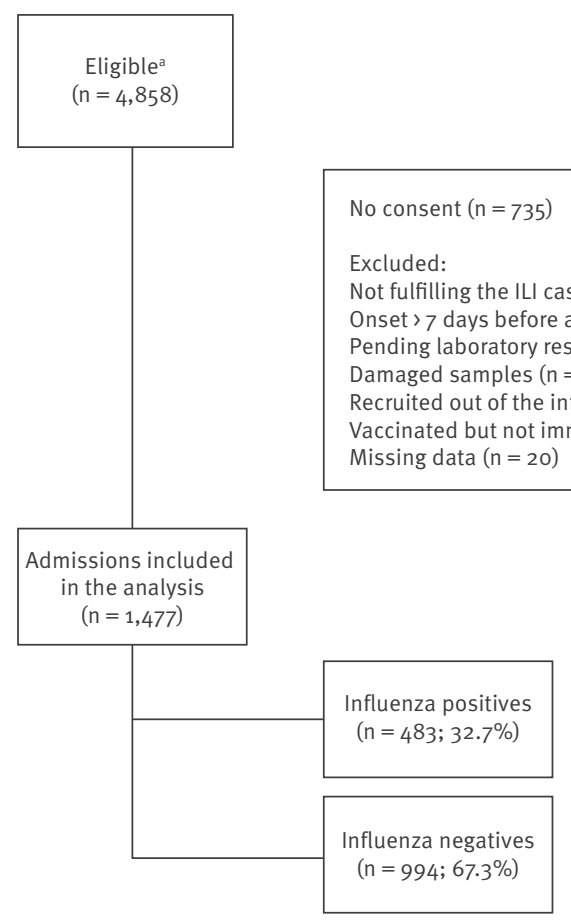

ILI: influenza-like illness.

a Individuals were eligible if they were patients $\geq 60$ years old admitted in hospital through the emergency department with a diagnosis possibly related to influenza, resident in one of the participating hospitals' catchment area, not institutionalised and not discharged from a previous hospitalisation episode in the 30 days prior to the current admission.

The trivalent influenza vaccine (TIV) for the 2017/18 northern hemisphere season included influenza A/Michigan/45/2015 $\left(\mathrm{H}_{1} \mathrm{~N}_{1}\right)$-like, A/ HongKong/4801/2014(H3N2)-like and B/ Brisbane/60/2008(Victoria-lineage)-like antigens [5] and was offered free of charge for persons aged $\geq 60$ years in the Valencia Region of Spain. The vaccine impact on infections with influenza $\mathrm{A}\left(\mathrm{H}_{3} \mathrm{~N}_{2}\right)$ for this season was expected to be low, as subclades 3 C.2a1, 3 C.2a2, 3 C.2a3 and 3 C.2a4 emerged within vaccine virus clade 3 C.2a, each subclade with particular mutations compared with the A/HongKong/4801/2014 $\left(\mathrm{H}_{3} \mathrm{~N}_{2}\right)$ vaccine component [6]. Although different viruses' distribution patterns were observed among European countries [7], the 2017/18 season was characterised in Europe by the co-circulation of influenza $A\left(\mathrm{H}_{1} \mathrm{~N}_{1}\right)$ pdmo9, $A\left(\mathrm{H}_{3} \mathrm{~N}_{2}\right)$ and $B /$ Yamagata lineage $[8,9]$, the latter not included in the trivalent vaccine.

Interim effectiveness analysis in the $2017 / 18$ season in Europe found a moderate effectiveness of the vaccine to prevent any influenza, including influenza B/
Yamagata lineage despite not being included in the vaccine $[10,11]$. The impact of previous vaccinations on current season IVE has been widely discussed [12,13]. Repeated vaccination has been observed to impair vaccine effectiveness against $A\left(\mathrm{H}_{1} \mathrm{~N}_{1}\right)$ pdmog [14] and against $A\left(\mathrm{H}_{3} \mathrm{~N}_{2}\right)$ [15]. Several studies, however, encourage current season vaccination regardless of vaccination history $[14,16]$, arguing that repeated vaccination is protective even in the presence of potential vaccination interference, with similar results in hospitalised and ambulatory patients [17-19]. In hospitalised older adults ( $\geq 65$ years old), repeated vaccination has been reported twice as effective in preventing severe influenza compared with non-severe influenza [19].

Since 2009, the Valencia Hospital Network for the Study of Influenza (VAHNSI) has conducted annually a prospective active-surveillance hospital-based study in the Valencia Region in Spain to explore the epidemiology of influenza viruses and to estimate the influenza vaccine effectiveness (IVE) in hospitalised patients against laboratory-confirmed influenza (LCI) [20-22].

We report here IVE estimates in hospitalised patients $\geq 6$ o years old against $\mathrm{LCl}$ in the 2017/18 influenza season in the Valencia Region in Spain. IVE was estimated for all influenza, by influenza strain and by vaccine type. The impact of prior vaccination was also estimated considering the vaccination history in the two previous influenza seasons.

\section{Methods}

\section{Study procedures}

The prospective active-surveillance observational study was carried out in four hospitals in the Valencia Region: Hospital General de Castellón (Castellón, Spain), Hospital La Fe (Valencia, Spain), Hospital Doctor Peset (Valencia, Spain) and Hospital General de Alicante (Alicante, Spain). Those hospitals provided healthcare to $1,105,570(22 \%)$ inhabitants of the Valencia Region.

Study procedures have been previously described [21]. Briefly, study staff screened consecutive hospitalised patients who had been discharged from the emergency department in order to be further admitted as inpatients. Patients were eligible for the study if they were $\geq 60$ years old, admitted in hospital through the emergency department with a diagnosis possibly related to influenza, resident in one of the participating hospitals' catchment area, not institutionalised and not discharged from a previous hospitalisation episode in the 30 days prior to the current admission. For inclusion in the analysis, patients had to have signed a written informed consent and had to have reported symptoms of influenza-like illness (ILI, defined as per the European Union ILI-case definition [23], as fever or feverishness, malaise, myalgia or headache and shortness of breath, sore throat or cough), which had occurred in the 7 days prior to admission to the 
Admissions with laboratory-confirmed influenza in patients $\geq 60$ years old, with influenza positivity percentages shown by epidemiological week, Valencia Hospital Network for the Study of Influenza (VAHNSI), Spain, 2017/18 influenza season $(\mathrm{n}=483$ patients)

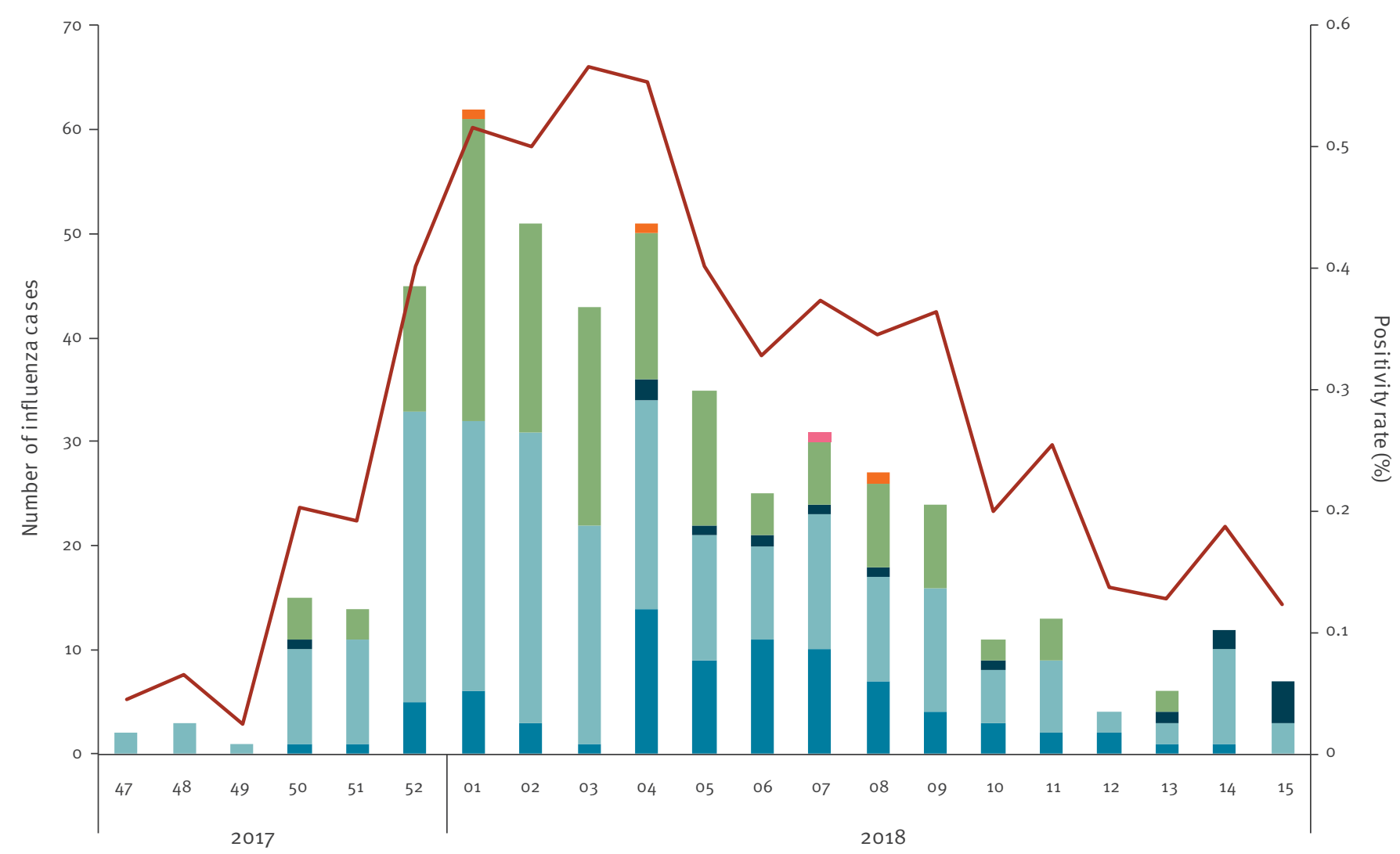

Year-epidemiological week at admission

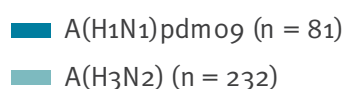

A not subtyped $(n=15)$
B/Yamagata $(n=150)$
B/Victoria $(n=1)$
B not subtyped $(n=4)$
_ Influenza positivity rate emergency department. Individuals were considered immunised if they had received the current season's influenza vaccine at least 15 days before symptoms onset. Vaccinated patients who were not immunised at the time of onset of symptoms were excluded from the analysis. The analysis was restricted to patients who had been recruited during the influenza season, defined as the period between the first of two consecutive weeks with two or more influenza cases detected in our hospital network and the previous week to the first of two consecutive weeks with no influenza cases detected in the network. Patients with damaged samples, pending laboratory results or missing data on the laboratory results outcome, main exposure variable (i.e. vaccination status or vaccine type) or covariates included in the model were excluded from the analysis.

\section{Ethical statement}

The Ethics Research Committee of the Dirección General de Salud Pública-Centro Superior de Investigación en Salud Pública (DGSP-CSISP) approved the protocol of the study. All patients signed a written informed consent before their inclusion in the study.

\section{Vaccine Information System}

Information related to influenza vaccination such as administration date of the vaccine, brand, batch and manufacturer was obtained from the Valencia Region Vaccine Information System (VRVIS) for all patients included in the study. VRVIS is a population-based register that records vaccine doses given at public and private healthcare facilities (primary care centres, hospitals, residential facilities in the public sector and any private sector healthcare facility that applies for access). The sensitivity and specificity of VRVIS was estimated to be $90 \%$ and $99 \%$, respectively $[21,24]$. The VRVIS is linked to inpatient and outpatient clinical records and sociodemographic information through a personal identification number. 


\section{Laboratory procedures}

Nasopharyngeal and pharyngeal swabs were obtained within the first 48 hours of admission from patients fulfilling the inclusion criteria. Both swabs were combined in one tube of viral transport media (Copan, Italy) and shipped refrigerated to a centralised virology laboratory at FISABIO-Public Health. One third of the viral transport media volume was used for extraction of total nucleic acids using an automated silicabased method (Nuclisens Easy-Mag, BioMérieux, Lyon, France). Extracted nucleic acids were tested for influenza viruses by multiplex real-time reverse transcription-PCR (RT-PCR), following WHO protocols [25] with the qScript XLT One-Step RT-qPCR ToughMix (Quanta BioSciences, Maryland, United States (US)) in a Lightcycler 480ll apparatus (Roche Diagnostics, Spain). First, a real-time RT-PCR screening assay was performed to detect and differentiate influenza $A$ and $B$ viruses using different primers and probes for the matrix protein [26]. Thereafter, two different real-time RT-PCR typing assays were performed to determine the viral subtype/lineage of influenza $A$ or $B$ viruses on influenza-positive samples [27,28].

Molecular characterisation of influenza $A\left(\mathrm{H}_{3} \mathrm{~N}_{2}\right)$, $\mathrm{A}\left(\mathrm{H}_{1} \mathrm{~N}_{1}\right)$ pdmo9, B/Yamagata or B/Victoria viruses was performed by haemagglutinin (HA) gene sequencing. All isolates from hospitalised cases with sufficient viral load $(\mathrm{Ct}<25)$ were systematically selected and a specific end-point RT-PCR amplification protocol was applied using different HA-specific primer sets for the corresponding virus type and subtype [28]. The amplified fragments (complete HA coding region) were sequenced by the Sanger method with the BigDye Direct Cycle Sequencing Kit in an ABI 3730xl DNA sequencer (Applied Biosystems, Life Technologies, Foster City, California, US) using specific primers to the corresponding virus type and subtype [28] at the Genomics Core of the Servei Central de Suport a la Investigació Experimental (SCSIE) in the University of Valencia, Spain. The obtained sequences were deposited in the Global Initiative on Sharing All Influenza Data (GISAID) database under accession numbers: EPI_ISL_369223, EPI_ISL_369224, EPI_ISL_369225, EPI_ISL_369226, EPI_ISL_369227, EPI_ISL_369228, EPI_ISL_369229, EPI_ISL_369230, EPI_ISL_369231, EPI_ISL_369232, EPI_ISL_369233, EPI_ISL_369234, EPI_ISL_369235, EPI_ISL_369236, EPI_ISL_369237, EPI_ISL_369238, EPI_ISL_369239, EPI_ISL_369240, EPI_ISL_369241, EPI_ISL_369242, EPI_ISL_369243, EPI_ISL_369244, EPI_ISL_369245, EPI_ISL_369246, EPI_ISL_369247, EPI_ISL_369248, EPI_ISL_369249, EPI_ISL_369250, EPI_ISL_369251, EPI_ISL_369252, EPI_ISL_369253, EPI_ISL_369254, EPI_ISL_369255, EPI_ISL_369256, EPI_ISL_369257, EPI_ISL_369258, EPI_ISL_369259, EPI_ISL_369260, EPI_ISL_369261, EPI_ISL_369262, EPI_ISL_369263, EPI_ISL_369264, EPI_ISL_369265, EPI_ISL_369266, EPI_ISL_369267, EPI_ISL_369268, EPI_ISL_369269, EPI_ISL_369270, EPI_ISL_369271, EPI_ISL_369272, EPI_ISL_369273, EPI_ISL_369274, EPI_ISL_369275, EPI_ISL_369276, EPI_ISL_369277,
EPI_ISL_369278, EPI_ISL_369279, EPI_ISL_369280, EPI_ISL_369281, EPI_ISL_369447, EPI_ISL_369448, EPI_ISL_369449, EPI_ISL_369450, EPI_ISL_369451, EPI_ISL_369452, EPI_ISL_369453, EPI_ISL_369454, EPI_ISL_369455, EPI_ISL_369456, EPI_ISL_369457, EPI_ISL_369458, EPI_ISL_369459, EPI_ISL_369460, EPI_ISL_369461, EPI_ISL_369462, EPI_ISL_369463, EPI_ISL_369464, EPI_ISL_369465, EPI_ISL_369466, EPI_ISL_369467, EPI_ISL_369468, EPI_ISL_369469, EPI_ISL_369470, EPI_ISL_369471, EPI_ISL_369472, EPI_ISL_369473, EPI_ISL_369474, EPI_ISL_369475, EPI_ISL_369520.

\section{Genetic analysis of influenza viruses}

Genetic characterisation of influenza $A\left(\mathrm{H}_{3} \mathrm{~N}_{2}\right), A\left(\mathrm{H}_{1} \mathrm{~N}_{1}\right)$ pdmo9, B/Yamagata or B/Victoria viruses was performed by comparison of the obtained HA sequences from the clinical isolates with representative and reference HA sequences (Supplement S1) obtained from the GISAID database (www.gisaid.org). An alignment of reference sequences with sample sequences was generated with the Clustal $\mathrm{W}$ algorithm integrated in the BioEdit software version 7.2.5 (http://www.mbio. ncsu.edu/bioedit/bioedit.html). Phylogenetic trees were inferred using maximum-likelihood methods and the best-fitting nt substitution model with the online PhyML platform (http://www.atcg-montpellier.fr/ phyml). Branch reliability was evaluated by approximate likelihood-ratio tests [29].

\section{Statistical analysis}

Differences between $\mathrm{LCl}$ and non-LCl hospitalised patients were assessed performing a Chi-squared test or a Fisher exact test as appropriate. We used the same tests when comparing vaccinated and unvaccinated individuals. All probabilities were two-tailed and $p$ values under 0.05 were considered statistically significant.

The test-negative design, a variation of the case-control study, was used to estimate IVE $[30,31]$. According to this approach, patients were enrolled, in our case in hospitals, based on an established case definition. Cases were $\mathrm{LCl}$ admitted patients and controls were non-LCl admitted patients. The adjusted odds ratio (aOR) was estimated using a mixed effects logistic regression model including potential confounders such as age, sex, number of underlying conditions, obesity status (obese defined as a body mass index, $\mathrm{BMI}, \geq 30$ ), previous admission in the last 12 months, number of general practitioner (GP) consultations in the last 3 months, smoking habits, socioeconomic status according to occupation [32], days from onset of symptoms to swabbing and hospital as fixed effects, and epidemiological week at admission as random effect. IVE was calculated as $(1-\mathrm{aOR}) \times 100 \%$, comparing the odds of vaccination among $\mathrm{LCl}$ cases and non$\mathrm{LCl}$ cases. Analyses were repeated by strain $\left(\mathrm{A}\left(\mathrm{H}_{3} \mathrm{~N}_{2}\right)\right.$, $\mathrm{A}\left(\mathrm{H}_{1} \mathrm{~N}_{1}\right)$ pdmo9, $\mathrm{B} /$ Yamagata lineage), by vaccine type (adjuvanted or non-adjuvanted) and according to current and prior two seasons influenza vaccination taking 
TABLE 1

Characteristics of patients $\geq 60$ years old admitted to hospital and included in the influenza vaccine effectiveness study, Valencia Hospital Network for the Study of Influenza (VAHNSI), Spain, 2017/18 influenza season ( $\mathrm{n}=1,477$ patients)

\begin{tabular}{|c|c|c|c|c|c|c|c|c|c|}
\hline \multirow[t]{2}{*}{ Characteristics } & \multicolumn{2}{|c|}{$\begin{array}{l}\text { Influenza } \\
\text { positive }\end{array}$} & \multicolumn{2}{|c|}{$\begin{array}{l}\text { Influenza } \\
\text { negative }\end{array}$} & \multirow[t]{2}{*}{ p value ${ }^{c}$} & \multirow[t]{2}{*}{ Number vaccinated in $2017 / 18$} & \multirow[t]{2}{*}{ Total } & \multirow[t]{2}{*}{$\%^{d}$} & \multirow[t]{2}{*}{$\mathrm{p}$ value } \\
\hline & $\mathrm{n}$ & $\%^{a}$ & $\mathrm{n}$ & $\%^{\mathrm{b}}$ & & & & & \\
\hline Overall $(n=1,477)$ & 483 & 32.7 & 994 & 67.3 & NA & 759 & 1,477 & 51.4 & NA \\
\hline \multicolumn{10}{|l|}{ Age in years } \\
\hline $60-69$ & 88 & 18.2 & 203 & 20.4 & \multirow{4}{*}{0.218} & 99 & 291 & 34.0 & \multirow{4}{*}{$<0.001$} \\
\hline $70-79$ & 166 & 34.4 & 289 & 29.1 & & 244 & 455 & 53.6 & \\
\hline $80-89$ & 177 & 36.6 & 384 & 38.6 & & 327 & 561 & 58.3 & \\
\hline$\geq 90$ & 52 & 10.8 & 118 & 11.9 & & 89 & 170 & 52.4 & \\
\hline \multicolumn{10}{|l|}{ Sex } \\
\hline Male & 234 & 48.4 & 526 & 52.9 & \multirow{2}{*}{0.107} & 420 & 760 & 55.3 & \multirow{2}{*}{0.002} \\
\hline Female & 249 & 51.6 & 468 & 47.1 & & 339 & 717 & 47.3 & \\
\hline \multicolumn{10}{|c|}{ Underlying conditions (number) } \\
\hline None & 29 & 6.0 & 76 & 7.6 & \multirow{3}{*}{0.181} & 35 & 105 & 33.3 & \multirow{3}{*}{$<0.001$} \\
\hline One & 122 & 25.3 & 214 & 21.5 & & 154 & 336 & 45.8 & \\
\hline Two or more & 332 & 68.7 & 704 & 70.8 & & 570 & 1,036 & 55.0 & \\
\hline \multicolumn{10}{|c|}{ Admission in the last 12 months } \\
\hline Yes & 140 & 29.0 & 346 & 34.8 & \multirow{2}{*}{0.025} & 485 & 991 & 48.9 & \multirow{2}{*}{0.007} \\
\hline No & 343 & 71.0 & 648 & 65.2 & & 274 & 486 & 56.4 & \\
\hline GP visits in the last 3 & & & & & & & & & \\
\hline None & 145 & 30.0 & 314 & 31.6 & & 223 & 459 & 48.6 & \\
\hline One & 56 & 11.6 & 116 & 11.7 & 0.814 & 82 & 172 & 47.7 & 0.126 \\
\hline Two or more & 282 & 58.4 & 564 & 56.7 & & 454 & 846 & 53.7 & \\
\hline Smoking habits & & & & & & & & & \\
\hline Never & 256 & 53.0 & 427 & 43.0 & & 350 & 683 & 51.2 & \\
\hline Ex-smoker & 158 & 32.7 & 425 & 42.8 & $<0.001$ & 336 & 583 & 57.6 & $<0.001$ \\
\hline Current smoker & 69 & 14.3 & 142 & 14.3 & & 73 & 211 & 34.6 & \\
\hline Socioeconomic statu & & & & & & & & & \\
\hline Professional & 57 & 11.8 & 119 & 12.0 & & 88 & 176 & 50.0 & \\
\hline Skilled & 43 & 8.9 & 93 & 9.4 & 0.953 & 76 & 136 & 55.9 & 0.527 \\
\hline Unskilled & 383 & 79.3 & 782 & 78.7 & & 595 & 1,165 & 51.1 & \\
\hline Obesity ${ }^{f}$ & & & & & & & & & \\
\hline No & 356 & 73.7 & 733 & 73.7 & & 556 & 1,089 & 51.1 & \\
\hline Yes & 127 & 26.3 & 261 & 26.3 & 0.988 & 203 & 388 & 52.3 & 0.669 \\
\hline Days from onset to $s$ & & & & & & & & & \\
\hline $0-2$ & 74 & 15.3 & 175 & 17.6 & & 131 & 249 & 52.6 & \\
\hline $3-4$ & 212 & 43.9 & 387 & 38.9 & 0.310 & 300 & 599 & 50.1 & 0153 \\
\hline $5-7$ & 157 & 32.5 & 348 & 35.0 & 0.310 & 274 & 505 & 54.3 & 0.153 \\
\hline 27 & 40 & 8.3 & 84 & 8.5 & & 54 & 124 & 43.5 & \\
\hline Current and prior vac & & & & & & & & & \\
\hline Vaccinated 2017/18 & 242 & 50.1 & 517 & 52.0 & 0.491 & $\mathrm{NA}$ & $\mathrm{NA}$ & NA & $\mathrm{NA}$ \\
\hline Vaccinated $2016 / 17$ & 241 & 49.9 & 528 & 53.1 & 0.245 & 663 & 769 & 86.2 & $<0.001$ \\
\hline Vaccinated 2015/16 & 254 & 52.6 & 544 & 54.7 & 0.439 & 651 & 798 & 81.6 & $<0.001$ \\
\hline Influenza test results & & & & & & & & & \\
\hline Negative & 0 & 0.0 & 994 & 100.0 & NA & 517 & 994 & 52.0 & 0.491 \\
\hline $\mathrm{A}(\mathrm{H} 1 \mathrm{~N} 1) \mathrm{pdmog}$ & 81 & 16.8 & 0 & 0.0 & NA & 30 & 81 & 37.0 & 0.008 \\
\hline $\mathrm{A}\left(\mathrm{H}_{3} \mathrm{~N}_{2}\right)$ & 232 & 48.0 & 0 & 0.0 & NA & 132 & 232 & 56.9 & 0.067 \\
\hline $\mathrm{B} /$ Yamagata lineage & 150 & 31.1 & o & 0.0 & NA & 69 & 150 & 46.0 & 0.405 \\
\hline B/Victoria lineage & 1 & 0.2 & o & 0.0 & NA & 1 & 1 & 0.0 & 0.272 \\
\hline
\end{tabular}

GP: general practitioner.

a Except for the 'Overall' category line of the Table, where the percentages are calculated relative to the total number of patients included in the analysis (i.e. 1,477), the rest of the percentages presented in this column are based on the total of patients testing positive for influenza (i.e. 483).

${ }^{b}$ Except for the 'Overall' category line of the Table, where the percentages are calculated relative to the total number of patients included in the analysis (i.e. 1,477 ), the rest of the percentages presented in this column are based on the total of patients testing negative for influenza (i.e. 994 ).

${ }^{c}$ These $\mathrm{p}$ values identify whether there is a dependence between the laboratory-confirmed influenza variable and the characteristics on the left, e.g. age. $\mathrm{P}$ values $<0.05$ indicate that influenza cases and influenza controls were not equally distributed according to the explored characteristics on the left.

d Percentages in this column are based on the numbers and totals displayed in the two previous columns.

e Socioeconomic status: 'professional' includes professionals, managers, medium or superior technicians, small entrepreneurs, middle managers, supervisors; 'skilled' includes skilled manual workers; 'unskilled' includes semi-skilled and unskilled manual workers.

f Obesity was defined as a body mass index $(B M I) \geq 30$.

${ }^{\mathrm{g}}$ Fifteen influenza $A$ and four influenza B samples were not subtyped because of low viral loads.

Bold font is used to highlight $p$ values indicating statistical significance. 
no vaccination in any of the three considered seasons as the reference category.

All statistical analyses were carried out in Stata version 14 (StataCorp, College Station, Texas).

\section{Results}

\section{Study participants and period}

After excluding from eligible persons, individuals who did not fulfil the inclusion criteria for the study, the analysis comprised a total of 1,477 hospital admissions among patients $\geq 6$ oyears old (Figure 1 ). The VAHNSI $2017 / 18$ influenza period was from week 47 of 2017 to week 15 of 2018 (Figure 2). The first LCl and last LCI cases were admitted on 20 November 2017 and the 11 April 2018, respectively.

Our data revealed that the 2017/18 influenza season in the Valencia Region in Spain was characterised by the co-circulation of influenza $A\left(\mathrm{H}_{1} \mathrm{~N}_{1}\right)$ pdmo9, $A\left(\mathrm{H}_{3} \mathrm{~N}_{2}\right)$ and $B /$ Yamagata lineage viruses. The epidemic waves of influenza $A\left(\mathrm{H}_{3} \mathrm{~N}_{2}\right)$ and $B /$ Yamagata lineage viruses were situated at the beginning of the season and the wave of influenza $A\left(\mathrm{H}_{1} \mathrm{~N}_{1}\right)$ pdmog viruses in the second half of the influenza season (Figure 2).

\section{Influenza positives vs influenza negatives}

A total of 483 hospitalised patients (32.7\%) were $\mathrm{LCl}$. Of these, 81 were infected with influenza $A\left(\mathrm{H}_{1} \mathrm{~N}_{1}\right)$ pdmog (16.8\%), $232 \mathrm{~A}\left(\mathrm{H}_{3} \mathrm{~N}_{2}\right)$ (48.0\%), $150 \mathrm{~B} /$ Yamagata lineage (31.1\%) virus strains and one was infected with an influenza B/Victoria lineage virus (0.2\%). Fifteen (3.1\%) influenza A and four (0.8\%) influenza B infected patients remained not subtyped because of low viral loads (Table 1).

Hospitalisation during the preceding year was more common among non-LCl than $\mathrm{LCl}$ hospitalised patients (34.8 vs $29.0 \%$ ). In terms of smoking habits, most of the $\mathrm{LCl}$ hospitalised patients (53.0\%) never smoked vs $43.0 \%$ of non- $\mathrm{LCl}$ admissions. (Table 1 ).

\section{Vaccinated vs unvaccinated individuals}

Overall, 1,240 (84.0\%) individuals had a vaccination record for any type of vaccine (influenza or other) in VRVIS. Of the $237(16.0 \%)$ individuals not in the registry, $230(97.0 \%)$ reported not being vaccinated. The 237 patients not included in the registry were considered as not vaccinated. Overall, 759 (51.4\%) and 718 (48.6\%) admissions were in vaccinated and unvaccinated patients with the $2017 / 18$ seasonal influenza vaccine, respectively. Vaccination coverage increased significantly with age and with the number of underlying conditions. Most of the vaccinated individuals were men $(55.3 \% ; 420 / 759)$. Never-smokers or ex-smokers were more often vaccinated than current smokers (51.2\% and $57.6 \%$ vs $34.6 \%$; p 0.001 ). Most of the patients vaccinated in the current season were also vaccinated in the two previous seasons, with 663 of them (87.3\%) also vaccinated in $2016 / 17$ and 651
(85.8\%) also vaccinated in 2015/16 (Table 1). Among vaccinees, $339(44.7 \%)$ received the adjuvanted vaccine and 411 (54.1\%) the non-adjuvanted vaccine. Vaccine type was unknown for nine (1.2\%) vaccinated individuals (data not shown).

\section{Viral genetic analysis}

The detailed genetic characterisation, mutational pattern and concordance of the different genetic groups with the vaccine and reference strains was performed using the complete HA coding sequence. Influenza $\mathrm{A}\left(\mathrm{H}_{3} \mathrm{~N}_{2}\right)$ viruses in circulation in Europe at the time of sampling corresponded to the genetic clades 3 C.3a and $3 \mathrm{C} .2 \mathrm{a}$, with clade $3 \mathrm{C} .2 \mathrm{a}$ viruses predominating, but with the HA gene sequences characterised by a quite divergent genetic composition. Among clade $3 \mathrm{C} .2 \mathrm{a}$, new subclades and subgroups have emerged (i.e. subclades 3C.2a1, 3C.2a2, 3C.2a3 and 3C.2a4) [33].

All the $33 \mathrm{~A}\left(\mathrm{H}_{3} \mathrm{~N}_{2}\right)$ isolates sequenced in this study corresponded to either subclades 3 C.2a1 (A/Singapore/ INFIMH-16-0019/2016-like $\quad(n=11)$ or 3 C.2a2 (A/ Nantes/1441/2017-like $)(n=22)$ viruses, different to the $\mathrm{A} /$ HongKong/4801/2014 (clade $3 \mathrm{C} .2 \mathrm{a}$ ) vaccine virus, and including changes in antigenic sites and in glycosylation patterns. All 113 C.2a1 viruses could be further classified as subgroup 3 C.2a1b (A/Singapore/ INFIMH-16-0019/2016-like), with in HA1 a N121K (site D) mutation and in $\mathrm{HA}_{2}, 1406 \mathrm{~V}$ and $\mathrm{G} 484 \mathrm{E}$, when compared with the $A / H o n g K o n g / 4801 / 2014$ vaccine virus. Additional mutational patterns further characterised three types of isolates: (i) $\mathrm{E} 62 \mathrm{G}+\mathrm{Q} 80 \mathrm{~K}+\mathrm{K} 92 \mathrm{R}$ (site D) $+\mathrm{N} 122 \mathrm{D}+\mathrm{T} 135 \mathrm{~K}$ (site A, loss of glycosylation) $+\mathrm{R} 142 \mathrm{G}$ (site $A)$ in $\mathrm{HA}_{1}$ and $\mathrm{S}_{432} \mathrm{~T}$ in $\mathrm{HA}_{2}(\mathrm{n}=3$, including two from vaccinees); (ii) $\mathrm{E} 62 \mathrm{G}+\mathrm{K} 92 \mathrm{R}$ (site D) + N122D + T135 (site $A$, loss of glycosylation) $+\mathrm{R} 142 \mathrm{G}$ (site $\mathrm{A}$ ) in $\mathrm{HA}_{1}$ and $S_{432} \mathrm{~T}$ in $\mathrm{HA}_{2}(\mathrm{n}=1$, from a vaccinee); and (iii) $\mathrm{E} 62 \mathrm{G}+\mathrm{K} 92 \mathrm{R}$ (site D) $+\mathrm{T}_{128} \mathrm{~A}+\mathrm{T}_{135} \mathrm{~K}$ (site A, loss of glycosylation) $+\mathrm{R}_{142} \mathrm{G}$ (site $\left.A\right)$ in $\mathrm{HA}_{1}(n=7$, four from vaccinees). In the 22 subclade 3 C.2a2 viruses, two main patterns were observed when compared with the $\mathrm{A} /$ HongKong/4801/2014 vaccine virus: (i) $\mathrm{R} 142 \mathrm{~K}$ (site $A)+R 261 Q$ alone $(n=1$, from vaccinee); and (ii) $\mathrm{T} 131 \mathrm{~K}+\mathrm{R} 142 \mathrm{~K}$ (site A) + R261Q (site E) as a common pattern ( $n=21,13$ from vaccinees). The latter viruses could be further differentiated in those without additional mutations ( $n=13$, nine from vaccinees); and those with additional mutations $\mathrm{Y}_{94 \mathrm{~K}}$ (site $\left.\mathrm{E}\right)(\mathrm{n}=1$, from a nonvaccinee); S144R (site $A)(n=5$, two from vaccinees); or S144R (site A) + S265G ( $n=2$, both from vaccinees).

All nine $A\left(\mathrm{H}_{1} \mathrm{~N}_{1}\right)$ pdmog viruses sequenced fell into clade 6B.1 within the A/Paris/1447/2017 subgroup, differentiated from the $A / M i c h i g a n / 45 / 2015$ vaccine virus by mutations S74R (site Cb), S164T (site Sa, linked to change in glycosylation) and $1295 \mathrm{~V}$; with $(n=4$, one from vaccinee) or without ( $n=5$, two from vaccinees) the additional mutation T120A.

We detected only one case (a vaccinated individual) infected with an influenza B/Victoria lineage virus. The 


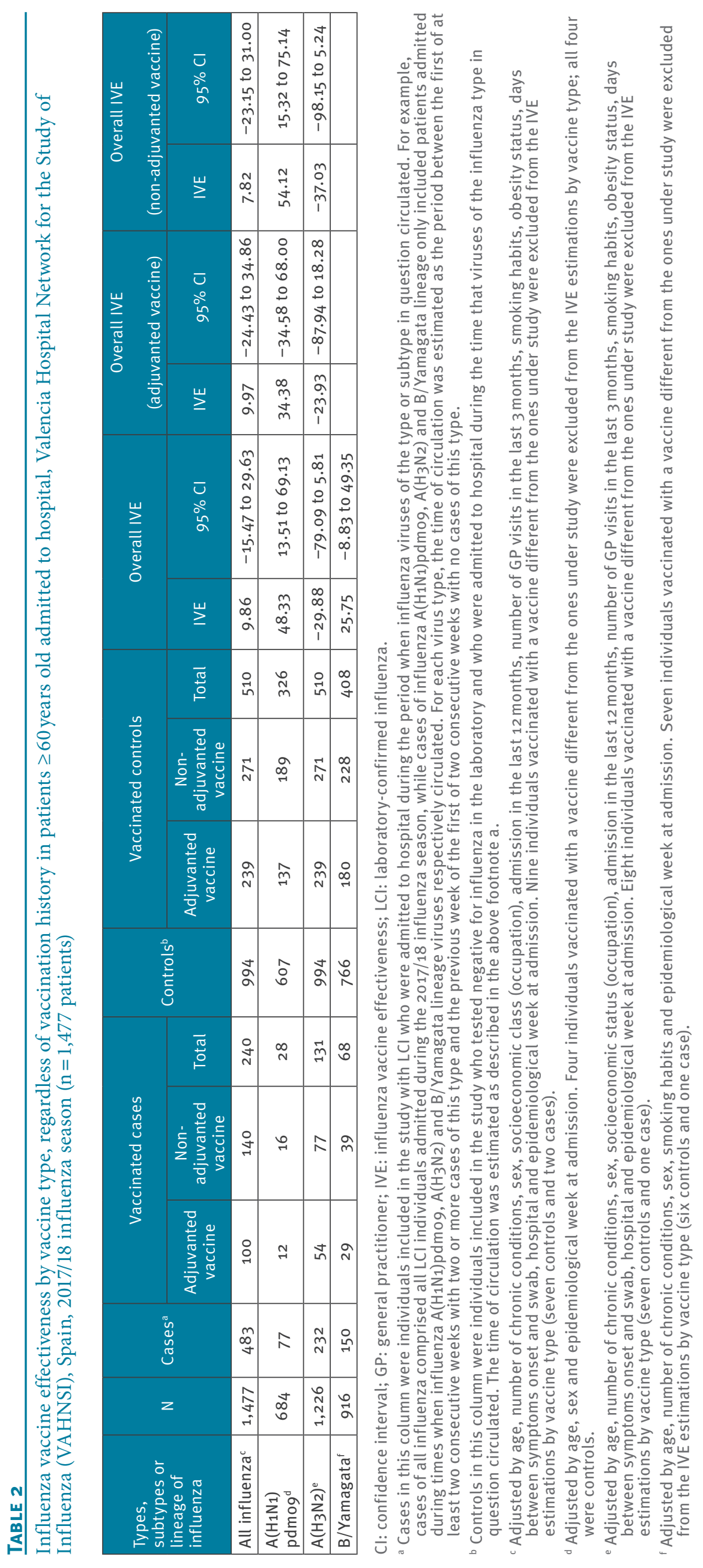


viral sequence corresponded to a clade $1 \mathrm{~A}$ sequence with $\mid 117 \mathrm{~V}+\mathrm{N} 129 \mathrm{D}$ and $\mathrm{a}$ two amino acid deletion (162-163) in the HA gene, both characteristic for a new genetic group B/Norway/2409/2017-like.

The $25 \mathrm{~B} /$ Yamagata lineage sequenced viruses all corresponded to clade 3 , B/Phuket/3073/2013-like, but differed by mutations $\mathrm{L} 172 \mathrm{Q}+\mathrm{M} 251 \mathrm{~V}$, with few isolates $(n=7)$ carrying additional mutations $H 85 Y$, E141R, V176I, V16ol or K335N.

Vaccine effectiveness in hospitalised patients Assessed IVE in patients $\geq 60$ years old admitted to hospital was $9.9 \%$ (95\% Cl: $-15.5 \%$ to $29.6 \%$ ), with no difference between the adjuvanted (IVE: 10.0\%; 95\% $\mathrm{Cl}:-24.4 \%$ to $34.9 \%)$ and the non-adjuvanted trivalent vaccine (IVE:7.8\%; 95\% Cl: $-23.1 \%$ to $31.0 \%$ ) $(p=0.1826$ for homogeneity of unadjusted odds; data not shown) (Table 2). The impact of previous vaccinations was not significant when considering effect on IVE (Table 3).

\section{Vaccine effectiveness against $\mathrm{A}(\mathrm{H} 1 \mathrm{~N} 1) \mathrm{pdm} 09$}

IVE assessed in hospitalised patients $\geq 60$ years old against $\mathrm{A}\left(\mathrm{H}_{1} \mathrm{~N}_{1}\right)$ pdmog was $48.3 \%$ (95\% Cl: $13.5 \%$ to $69.1 \%$ ) (Table 2). IVE was $34.4 \%$ (95\% Cl: $-34.6 \%$ to $68.0 \%)$ for the adjuvanted vaccine and $54.1 \%$ (95\% $\mathrm{Cl}: 15.3 \%$ to $75.1 \%)$ for the non-adjuvanted vaccine ( $p=0.9319$ for homogeneity of unadjusted odds; data not shown) (Table 2). When considering vaccination history and taking those individuals not vaccinated in any of the three considered seasons as reference category, we observed an IVE of $46.4 \%$ (95\% Cl: $6.8 \%$ to $69.2 \%$ ) in those individuals vaccinated in the current and in any of the two previous seasons. No statistically significant differences were found for those vaccinated only in the current season and for those vaccinated in any of the two previous seasons but not in the current one (Table 3).

\section{Vaccine effectiveness against $\mathrm{A}(\mathrm{H} 3 \mathrm{~N} 2)$}

IVE assessed in hospitalised patients $\geq 60$ years old against $\mathrm{A}\left(\mathrm{H}_{3} \mathrm{~N}_{2}\right)$ was $-29.9 \%$ (95\% Cl: $-79.1 \%$ to $\left.5.8 \%\right)$ (Table 2). IVE was $-23.9 \%$ (95\% Cl: $-87.9 \%$ to $18.3 \%$ ) for the adjuvanted vaccine and $-37.0 \%(95 \% \mathrm{Cl}:-98.1 \%$ to $5.2 \%)$ for the non-adjuvanted vaccine $(p=0.2480$ for homogeneity of unadjusted odds; data not shown) (Table 2). The impact of previous vaccinations was not significant when considering effect on IVE (Table 3).

\section{Vaccine effectiveness against $B$ /}

\section{Yamagata-lineage}

IVE assessed in hospitalised patients $\geq 60$ years old against B/Yamagata lineage was $25.7 \%$ (95\% Cl: $-8.8 \%$ to $49.3 \%$ ) (Table 2 ). IVE was $30.1 \%$ (95\% Cl: $-15.9 \%$ to $57.8 \%)$ for the adjuvanted vaccine and $21.1 \%$ (95\% $\mathrm{Cl}:-24.4 \%$ to $50.0 \%)$ for the non-adjuvanted vaccine $(p=0.8212$ for homogeneity of unadjusted odds; data not shown) (Table 2). When considering vaccination history and taking those individuals not vaccinated in any of the three considered seasons, we observed an IVE of $39.6 \%$ ( $95 \% \mathrm{Cl}: 8.1 \%$ to $60.3 \%$ ) in those individuals vaccinated in the current and in any of the two previous seasons and an IVE of $50.2 \%$ (95\% Cl: $2.3 \%$ to $74.6 \%)$ for those not vaccinated in the current season but in any of the two previous ones. No effectiveness (IVE: $4.5 ; 95 \% \mathrm{Cl}:-142.6 \%$ to $62.4 \%$ ) was observed for those vaccinated only in the current season (Table 3 ).

\section{Discussion}

During the $2017 / 18$ season we observed non-significant PCR-confirmed influenza vaccine effectiveness in hospitalised patient $s \geq 6$ oyears of age. There was nevertheless significant protection against influenza $\mathrm{A}\left(\mathrm{H}_{1} \mathrm{~N}_{1}\right)$ pdmo9, a subtype that circulated at low levels in Spain. In the country, the influenza season started earlier than in previous years and persisted for 21 weeks, up to 5 weeks longer than in the $2016 / 17$ season $[34,35]$, therefore having a higher social impact.

The 2017/18 influenza season in the northern hemisphere was characterised by co-circulation of different viruses, including $A\left(\mathrm{H}_{1} \mathrm{~N}_{1}\right)$ pdmo9, $A\left(\mathrm{H}_{3} \mathrm{~N}_{2}\right)$ and $B$. Between 88 to $94 \%$ of the influenza $B$ viruses corresponded to the Yamagata lineage $[10,11,36]$, mainly $B /$ Phuket/3073/2013(Yamagata-lineage)-like strain [10].

Most of the influenza $\mathrm{A}\left(\mathrm{H}_{3} \mathrm{~N}_{2}\right)$ isolates characterised in the current study corresponded to subclades 3 C.2a1 or 3 C.2a2, with several mutations, compared with the clade $3 \mathrm{C} 2 \mathrm{a} \mathrm{A} /$ HongKong/4801/2014 vaccine strain, including several antigenic sites and changes in glycosylation patterns. In the northern hemisphere, $63-71 \%$ of $A\left(\mathrm{H}_{3} \mathrm{~N}_{2}\right)$ isolated viruses belonged to the $A /$ HongKong/4801/2014-like strain, related to past season's A/Bolzano/7/2016 (3C.2a clade), which only represented $26 \%$ of the positives in the Spanish sentinel influenza network [37]. In Canada 93\% of the characterised $\mathrm{A}\left(\mathrm{H}_{3} \mathrm{~N}_{2}\right)$ viruses were clade $3 \mathrm{C} .2 \mathrm{a}$. Antisera raised against the egg-propagated vaccine virus $A$ / HongKong/4801/2014 recognised a small minority of circulating viruses in 3 C.2a subclades this season [38,39], suggesting a potential antigenic mismatch that could explain in part the poor IVE for the $A\left(\mathrm{H}_{3} \mathrm{~N}_{2}\right)$ component.

The $A\left(\mathrm{H}_{1} \mathrm{~N}_{1}\right)$ pdmog viruses analysed were clade 6B.1 with different mutations, but these $H A$ variants have been reported to be antigenically similar to the $A$ / Michigan/45/2015 vaccine-virus [40]. There was a moderate vaccine effectiveness against this virus, indicating that the antigenic mismatch between the circulating virus and the vaccine component was probably low. However, non-significant IVE was found in our study against influenza $A\left(\mathrm{H}_{1} \mathrm{~N}_{1}\right)$ pdmog in those vaccinated in the current season but not in any of the two previous seasons. Repeated vaccination against this influenza strain improved the IVE estimate although the strain included in the vaccine of the two previous seasons was $A / C a l i f o r n i a / 7 / 2009\left(\mathrm{H}_{1} \mathrm{~N}_{1}\right)$ pdmog-like virus. Caution should be taken because of small numbers when dividing individuals into groups. Our study 
Influenza vaccine effectiveness, considering vaccination history in the current and the two previous seasons in patients $\geq 60$ years old admitted to hospital, Valencia Hospital Network for the Study of Influenza (VAHNSI), Valencia, Spain, 2017/18 influenza season ( $\mathrm{n}=1,477$ patients)

\begin{tabular}{|c|c|c|c|c|}
\hline Types, subtypes or lineage of influenza & $\begin{array}{l}\text { Vaccinated } \\
\text { in either } 2015 / 16 \text { or } 2016 / 17^{a}\end{array}$ & $\begin{array}{l}\text { Vaccinated } \\
\text { in } 2017 / 18\end{array}$ & $\mathrm{IVE}^{\mathrm{b}}$ & $95 \% \mathrm{Cl}$ \\
\hline \multirow{3}{*}{ All influenzac } & No & Yes & 30.16 & -34.21 to 63.65 \\
\hline & Yes & Yes & 14.20 & -12.79 to 34.73 \\
\hline & Yes & No & 22.98 & -16.64 to 49.14 \\
\hline \multirow{3}{*}{$A\left(\mathrm{H}_{1} \mathrm{~N}_{1}\right) \mathrm{pdmog}^{\mathrm{d}}$} & No & Yes & 80.11 & -53.74 to 97.43 \\
\hline & Yes & Yes & 46.41 & 6.78 to 69.20 \\
\hline & Yes & No & 10.60 & -94.00 to 58.80 \\
\hline \multirow{3}{*}{$\mathrm{A}\left(\mathrm{H}_{3} \mathrm{~N}_{2}\right)^{\mathrm{e}}$} & No & Yes & -1.47 & -142.01 to 57.46 \\
\hline & Yes & Yes & -35.26 & -93.67 to 5.53 \\
\hline & Yes & No & -7.52 & -84.80 to 37.44 \\
\hline \multirow{3}{*}{$\mathrm{B} /$ Yamagata $^{\mathrm{f}}$} & No & Yes & 4.48 & -142.60 to 62.39 \\
\hline & Yes & Yes & 39.61 & 8.13 to 60.31 \\
\hline & Yes & No & 50.18 & 2.34 to 74.59 \\
\hline
\end{tabular}

$\mathrm{Cl}$ : confidence interval; GP: general practitioner; IVE: influenza vaccine effectiveness.

a The 2015/16 influenza vaccine comprised an A/California/7/2009 ( $\left.\mathrm{H}_{1} \mathrm{~N}_{1}\right)$ pdmo9-like virus, an A/Switzerland/9715293/2013 (H3N2)-like virus and a B/Phuket/3073/2013-like virus (Yamagata lineage). The 2016/17 influenza vaccine comprised an A/California/7/2009 (H1N1)pdmo9like virus, an A/Hong Kong/4801/2014 ( $\left.\mathrm{H}_{3} \mathrm{~N}_{2}\right)$-like virus and a B/Brisbane/6o/2008-like virus (Victoria lineage).

b Taking those individuals not vaccinated in any of the three considered seasons as reference category.

${ }^{c}$ Adjusted by age, number of chronic conditions, sex, socioeconomic status (occupation), admission in the last 12 months, number of GP visits in the last 3 months, smoking habits, obesity status, days between symptoms onset and swab, hospital and epidemiological week at admission.

${ }^{d}$ Adjusted by age, sex and epidemiological week at admission.

e Adjusted by age, number of chronic conditions, sex, socioeconomic status (occupation), admission in the last 12 months, number of GP visits in the last 3 months, smoking habits, obesity status, days between symptoms onset and swab, hospital and epidemiological week at admission.

${ }^{f}$ Adjusted by age, number of chronic conditions, sex, smoking habits and epidemiological week at admission.

focused on patients 60 years old or over and it is very common that those who were vaccinated in the current season were also vaccinated in the previous ones, resulting in a small number in the vaccinated only in the current season category.

Most of the influenza B viruses isolated in our study (150/155) corresponded to the Yamagata lineage, and the 25 sequenced isolates all belonged to clade 3, similar to the B/Phuket/3073/2013 vaccine strain. Although they showed additional substitutions (i.e. $\mathrm{L} 172 \mathrm{Q}+\mathrm{M} 251 \mathrm{~V}$ ), these variant viruses seem well recognised by antiserum raised against B/Phuket/3073/2013 vaccine virus, which belongs to the Yamagata lineage $[38,39]$. The B/Yamagata lineage was however not included in the 2017/18 trivalent vaccine and our study found low, non-significant trivalent IVE against influenza $\mathrm{B} /$ Yamagata-lineage. Mid-season reports in Europe [11] found decreasing protection of the vaccine against this mismatched lineage with age. In cases of influenza $B$ lineage mismatch between vaccine and circulating strains, a certain level of protection is expected as a result of residual effect of prior years' vaccination with the circulating lineage, and some degree of crossreactivity [41]. These reasons could explain the advantage of the repeated vaccination against influenza $B$ / Yamagata lineage we found in our study. Influenza B lineages are antigenically different and virus neutralising antibodies poorly cross-react between lineages [42]. However, studies in ferrets showed evidence of viral interference and cross-reactive immunity, with animals infected with one B lineage showing some degree of protection against subsequent challenge with either $B$ lineage [43]. This effect could be due to CD8 + cytotoxic $\mathrm{T}$-cells directed to one $\mathrm{B}$ lineage cross-reacting with antigens of the other lineage, even in absence of neutralising antibodies [42].

Concerning all influenza, due to the divergence between the circulating viruses and the trivalent vaccine content, a low vaccine effectiveness was expected $[6,44]$. In fact, IVE against all influenza was low and none of the two vaccines (adjuvanted or non-adjuvanted) offered significant protection. Mid-season interim reports, mainly describing outpatients surveillance systems in Europe $[10,11]$ already showed moderate protection, especially to $A\left(\mathrm{H}_{1} \mathrm{~N}_{1}\right)$ pdmog and $B$ infections and in younger populations. Although a moderate protection was reached against influenza $\mathrm{A}\left(\mathrm{H}_{1} \mathrm{~N}_{1}\right)$ pdmog in our study, the low circulation of this subtype in Spain prevented a large health impact of the vaccine. IVE against influenza $A\left(\mathrm{H}_{3} \mathrm{~N}_{2}\right)$ was null overall and by vaccine type. This finding is consistent with results obtained by other studies $[10,11,36]$ in any age group. 
Some published studies suggested that IVE is age dependent, with higher effectiveness in younger age groups and lower in the elderly, the groups where vaccination is mostly recommended $[45,46]$. There are differences among studies that make comparisons difficult, especially the level of care where the cases are collected. In general, IVE studied in hospitalised patients tends to be lower than IVE based on data from surveillance systems. The reason is unclear, but potential biases may be present in either study designs, primary care or hospital settings [47]. When assessing IVE, an ideal active comparator has a similar indication to the treatment or intervention of interest and is administered to a population with a similar distribution of measured and unmeasured patient characteristics [48]. This is sometimes difficult to assess in observational studies and may remain as a residual bias, but may have a lower impact in hospitalised, more fragile patients.

Our study has the typical limitations of an observational study. The absence of statistical significance and wide confidence intervals are common in studies with moderate to low IVE, low vaccine coverage and small sample size [49]. We restricted our analysis to periods with influenza circulation and we only considered patients fulfilling the ECDC ILI-case definition and an onset of symptoms in the 7 days prior to admission to control the heterogeneity in the study due to case ascertainment. Vaccination status was ascertained by registries, influenza was confirmed with a sensitive RT-PCR assay and only patients swabbed within $48 \mathrm{~h}$ of admission in hospital were included to avoid misclassification bias.

Our data support the importance of taking into account virological data and influenza vaccine effectiveness results to make better decisions during the challenging task of the seasonal vaccine composition choice. We also add valuable information regarding the controversial issue about the impact of previous vaccinations and influenza vaccine effectiveness for the different commercialised vaccines in the Valencia Region.

\section{Acknowledgements}

We gratefully acknowledge the originating and submitting laboratories who contributed the GISAID database sequences used in this phylogenetic analysis.

The authors thank the staff of Hospital General de Castellón in Castellón; La Fe, in Valencia; Hospital Dr Peset, in Valencia; Hospital General de Alicante, in Alicante for their support and contribution to the Valencia Hospital Network for the Study of Influenza and Respiratory Viruses Disease (VAHNSI) network. We thank all the study participants and their families.

\section{Conflict of interest}

AMI and VBM were funded by FISABIO-Public Health and Sanofi Pasteur. Sanofi Pasteur did not participate in the design, conduct of the study, analysis or decision to publish the results.

\section{Authors' contributions}

JDD: study coordinator and writing manuscript. AMI: data analysis and writing manuscript. FXLL molecular analysis and writing manuscript. VBM: data management and writing manuscript. JPB: writing manuscript. MTG, JMM, MCF, GSC: investigators. All authors reviewed and approved the definitive version of the manuscript.

\section{References}

1. World Health Organization (WHO). Vaccines against influenza WHO position paper - November 2012. Wkly Epidemiol Rec. 2012;87(47):461-76. PMID: 23210147

2. Simonsen L, Clarke MJ, Schonberger LB, Arden NH, Cox NJ, Fukuda K. Pandemic versus epidemic influenza mortality: a pattern of changing age distribution. J Infect Dis. 1998;178(1):53-60. https://doi.org/10.1086/515616 PMID: 9652423

3. Simonsen L, Reichert TA, Viboud C, Blackwelder WC, Taylor RJ, Miller MA. Impact of influenza vaccination on seasonal mortality in the US elderly population. Arch Intern Med. 2005;165(3):265-72. https://doi.org/10.1001/ archinte.165.3.265 PMID: 15710788

4. Webster RG, Bean WJ, Gorman OT, Chambers TM, Kawaoka Y. Evolution and ecology of influenza A viruses. Microbiol Rev. 1992;56(1):152-79. PMID: 1579108

5. World Health Organization (WHO). Composition recommandée des vaccins antigrippaux pour la saison grippale 2017-2018 dans l'hémisphère Nord. [Recommended composition of influenza virus vaccines for use in the 2017-2018 northern hemisphere influenza season]. Wkly Epidemiol Rec. 2017;92(11):117-28. PMID: 28303704

6. Rondy M, Gherasim A, Casado I, Launay O, Rizzo C, Pitigoi $\mathrm{D}$, et al. Low 2016/17 season vaccine effectiveness against hospitalised influenza $\mathrm{A}\left(\mathrm{H}_{3} \mathrm{~N}_{2}\right)$ among elderly: awareness warranted for 2017/18 season. Euro Surveill. 2017;22(41):1700645. https://doi.org/10.2807/1560-7917.ES.2017.22.41.1700645 PMID: 29043961

7. European Centre for Disease Prevention and Control (ECDC) World Health Organization (WHO) Regional Office for Europe. Flu News Europe, Joint ECDC-WHO weekly influenza update, week 20/2018. Geneva: WHO; Stockholm: ECDC. [Accessed 5 Feb 2019]. Available from: https://flunewseurope.org/Archives

8. Adlhoch C, Snacken R, Melidou A, Ionescu S, Penttinen PThe European Influenza Surveillance Network. Dominant influenza $\mathrm{A}\left(\mathrm{H}_{3} \mathrm{~N}_{2}\right)$ and $\mathrm{B} /$ Yamagata virus circulation in $\mathrm{EU} /$ EEA, 2016/17 and 2017/18 seasons, respectively. Euro Surveill. 2018;23(13):1800146. https://doi.org/10.2807/1560-7917. ES.2018.23.13.18-00146 PMID: 29616611

9. European Centre for Disease Prevention and Control (ECDC)/ World Health Organization (WHO) Regional Office for Europe. Flu News Europe, Joint ECDC-WHO weekly influenza update, week 18/2018. Geneva: WHO; Stockholm: ECDC. [Accessed 5 Feb 2019]. Available from: https://flunewseurope.org/Archives

10. Castilla J, Navascués A, Casado I, Pérez-García A, Aguinaga A, Ezpeleta G, et al. Interim effectiveness of trivalent influenza vaccine in a season dominated by lineage mismatched influenza B, northern Spain, 2017/18. Euro Surveill. 2018;23(7):1800057. https://doi.org/10.2807/1560-7917. ES.2018.23.7.18-00057 PMID: 29471624

11. Rondy M, Kissling E, Emborg HD, Gherasim A, Pebody $R$, Trebbien R, et al. Interim 2017/18 influenza seasonal vaccine effectiveness: combined results from five European studies. Euro Surveill. 2018;23(9):1800086. https://doi. org/10.2807/1560-7917.ES.2018.23.9.18-00086 PMID: 29510782

12. Belongia EA, Skowronski DM, McLean HQ, Chambers C, Sundaram ME, De Serres G. Repeated annual influenza vaccination and vaccine effectiveness: review of evidence. Expert Rev Vaccines. 2017;16(7): 723-36. https://doi.org/10.10 80/14760584.2017.1334554 PMID: 28562111

13. Skowronski DM, Chambers C, De Serres G, Sabaiduc S, Winter $A L$, Dickinson JA, et al. Serial vaccination and the antigenic distance hypothesis: Effects on influenza vaccine effectiveness during $\mathrm{A}\left(\mathrm{H}_{3} \mathrm{~N}_{2}\right)$ epidemics in Canada, 2010-11 to 2014-15. J Infect Dis. 2017;215(7):1059-99. https://doi.org/10.1093/ infdis/jixo74 PMID: 28180277 
14. Rondy M, Launay O, Castilla J, Costanzo S, Puig-Barberà J, Gefenaite G, et al. Repeated seasonal influenza vaccination among elderly in Europe: Effects on laboratory confirmed hospitalised influenza. Vaccine. 2017;35(34):4298-306. https://doi.org/10.1016/j.vaccine.2017.06.088 PMID: 28709555

15. Zhang L, Yang P, Thompson MG, Pan Y, Ma C, Wu S, et al. Influenza vaccine effectiveness in preventing influenza illness among children during school-based outbreaks in the 2014-2015 season in Beijing, China. Pediatr Infect Dis J. 2017;36(3):e69-75. https://doi.org/10.1097/ INF.0000000000001434 PMID: 27902651

16. McLean HQ, Thompson MG, Sundaram ME, Meece JK, McClure $D L$, Friedrich TC, et al. Impact of repeated vaccination on vaccine effectiveness against influenza $A\left(\mathrm{H}_{3} \mathrm{~N}_{2}\right)$ and $B$ during 8 seasons. Clin Infect Dis. 2014;59(10):1375-85. https://doi. org/10.1093/cid/ciu680 PMID: 25270645

17. Shim E, Smith KJ, Nowalk MP, Raviotta JM, Brown ST, DePasse J, et al. Impact of seasonal influenza vaccination in the presence of vaccine interference. Vaccine. $2018 ; 36(6): 853-8$ https://doi.org/10.1016/j.vaccine.2017.12.067 PMID: 29329684

18. Cheng AC, Macartney KK, Waterer GW, Kotsimbos T, Kelly PM, Blyth CC, et al. Repeated Vaccination Does Not Appear to Impact Upon Influenza Vaccine Effectiveness Against Hospitalization With Confirmed Influenza. Clin Infect Dis. 2017;64(11):1564-72. https://doi.org/10.1093/cid/cix209 PMID: 28329167

19. Casado I, Domínguez Á, Toledo D, Chamorro J, Astray J, Egurrola $M$, et al. Repeated influenza vaccination for preventing severe and fatal influenza infection in older adults: a multicentre case-control study. CMAJ. 2018;190(1):E3-12. https://doi.org/10.1503/cmaj.170910 PMID: 29311098

20. Puig-Barberà J, Arnedo-Pena A, Pardo-Serrano F, TiradoBalaguer MD, Pérez-Vilar S, Silvestre-Silvestre E, et al. Effectiveness of seasonal 2008-2009, 2009-2010 and pandemic vaccines, to prevent influenza hospitalizations during the autumn 2009 influenza pandemic wave in Castellón, Spain. A test-negative, hospital-based, case-control study. Vaccine. 2010;28(47):7460-7. https://doi.org/10.1016/j. vaccine.2010.09.042 PMID: 20875486

21. Puig-Barberà J, García-de-Lomas J, Díez-Domingo J, ArnedoPena A, Ruiz-García M, Limón-Ramírez R, et al. Influenza vaccine effectiveness in preventing influenza $A\left(\mathrm{H}_{3} \mathrm{~N}_{2}\right)$-related hospitalizations in adults targeted for vaccination by type of vaccine: a hospital-based test-negative study, 2011-2012 $\mathrm{A}\left(\mathrm{H}_{3} \mathrm{~N}_{2}\right)$ predominant influenza season, Valencia, Spain. PLoS One. 2014;9(11):e112294. https://doi.org/10.1371/journal. pone.0112294 PMID: 25392931

22. Puig-Barberà J, Mira-Iglesias A, Tortajada-Girbes M, LópezLabrador FX, Belenguer-Varea A, Carballido-Fernández M, et al. Effectiveness of influenza vaccination programme in preventing hospital admissions, Valencia, 2014/15 early results. Euro Surveill. 2015;20(8):21044. https://doi. org/10.2807/1560-7917.ES2015.20.8.21044 PMID: 25742432

23. European Commission. Commission Implementing Decision of 8 August 2012 amending Decision 2002/253/EC laying down case definitions for reporting communicable diseases to the Community network under Decision No 2119/98/EC of the European Parliament and of the Council (notified under document C(2012) 5538). Official Journal of the European Union. Luxembourg: Publications Office of the European Union. 27.9.2012:L 262/16. [Accessed 5 Feb 2019]. Available from: http://eur-lex.europa.eu/legal-content/EN/TXT/PDF/?uri=CELE $X: 32012$ D 0506\&qid $=1428573336660 \&$ from $=E N \# p a g e=16$

24. Puig-Barberà J, Natividad-Sancho A, Calabuig-Pérez J, LluchRodrigo JA, Pastor-Villalba E, Martínez-Úbeda S, et al. MF59adjuvanted and virosomal influenza vaccines for preventing influenza hospitalization in older people: comparative effectiveness using the Valencia health care information system. Vaccine. 2013;31(37):3995-4002. https://doi. org/10.1016/j.vaccine.2013.05.070 PMID: 23731629

25. World Health Organization (WHO). Real-time PCR group protocol \#2, WHO molecular diagnosis of influenza virus in humans, November 2012 update. November 2012. [Accessed 16 Jan 2014]. Available from: http://www.who.int/influenza/gisrs laboratory/molecular_diagnosis_influenza_virus_humans_ update_201211.pdf

26. He J, Bose ME, Beck ET, Fan J, Tiwari S, Metallo J, et al. Rapid multiplex reverse transcription-PCR typing of influenza $A$ and $B$ virus, and subtyping of influenza $A$ virus into $\mathrm{H}_{1}, 2,3,5,7,9$, $\mathrm{N}_{1}$ (human), N1 (animal), N2, and N7, including typing of novel swine origin influenza A ( $\left.\mathrm{H}_{1} \mathrm{~N}_{1}\right)$ virus, during the 2009 outbreak in Milwaukee, Wisconsin. J Clin Microbiol. 2009;47(9):2772-8. https://doi.org/10.1128/JCM.00998-09 PMID: 19641063

27. Suwannakarn K, Payungporn S, Chieochansin T, Samransamruajkit R, Amonsin A, Songserm T, et al. Typing $(A / B)$ and subtyping $\left(\mathrm{H}_{1} / \mathrm{H}_{3} / \mathrm{H}_{5}\right)$ of influenza $A$ viruses by multiplex real-time RT-PCR assays. J Virol
Methods. 2008;152(1-2):25-31. https://doi.org/10.1016/j. jviromet.2008.06.002 PMID: 18598722

28. World Health Organization (WHO). WHO molecular diagnosis of influenza virus in humans, August 2011 update. August 2011. [Accessed Aug 2014]. Available from: http://www.who. int/influenza/resources/documents/molecular_diagnosis_ influenza_virus_humans_update_201108.pdf

29. Guindon S, Dufayard JF, Lefort V, Anisimova M, Hordijk $W$, Gascuel $O$. New algorithms and methods to estimate maximum-likelihood phylogenies: assessing the performance of PhyML 3.0. Syst Biol. 2010;59(3):307-21. https://doi. org/10.1093/sysbio/syq010 PMID: 20525638

30. Jackson ML, Nelson JC. The test-negative design for estimating influenza vaccine effectiveness. Vaccine. 2013;31(17):21658. https://doi.org/10.1016/j.vaccine.2013.02.053 PMID: 23499601

31. Sullivan SG, Feng S, Cowling BJ. Potential of the test-negative design for measuring influenza vaccine effectiveness: a systematic review. Expert Rev Vaccines. 2014;13(12):157191. https://doi.org/10.1586/14760584.2014.966695 PMID: 25348015

32. Galobardes B, Shaw M, Lawlor DA, Lynch JW, Davey Smith G. Indicators of socioeconomic position (part 2). J Epidemiol Community Health. 2006;60(2):95-101. https://doi. org/10.1136/jech.2004.028092 PMID: 16415256

33. European Centre for Disease Prevention and Control (ECDC)/ World Health Organization (WHO) Regional Office for Europe. Flu News Europe, Joint ECDC-WHO weekly influenza update, week 48/2018. Geneva: WHO; Stockhom: ECDC. [Accessed 5 Feb 2019]. Available from: https://flunewseurope.org/Archives

34. Mira-Iglesias A, López-Labrador FX, Guglieri-López B, Tortajada-Girbés M, Baselga-Moreno V, Cano L, et al. Influenza vaccine effectiveness in preventing hospitalisation of individuals 60 years of age and over with laboratoryconfirmed influenza, Valencia Region, Spain, influenza season 2016/17. Euro Surveill. 2018;23(8):17-00318. https:// doi.org/10.2807/1560-7917.ES.2018.23.8.17-00318 PMID: 29486829

35. Puig-Barberà J, Guglieri-López B, Tortajada-Girbés M, LópezLabrador FX, Carballido-Fernández M, Mollar-Maseres J, et al. Low influenza vaccine effectiveness and the effect of previous vaccination in preventing admission with $A\left(\mathrm{H}_{1} \mathrm{~N}_{1}\right)$ pdmog or $B$ Victoria-Lineage in patients 60 years old or older during the 2015/2016 influenza season. Vaccine. 2017;35(52):7331-8. https://doi.org/10.1016/j.vaccine.2017.10.100 PMID: 29128380

36. Skowronski DM, Chambers C, De Serres G, Dickinson JA, Winter AL, Hickman R, et al. Early season co-circulation of influenza $\mathrm{A}\left(\mathrm{H}_{3} \mathrm{~N}_{2}\right)$ and $\mathrm{B}$ (Yamagata): interim estimates of 2017/18 vaccine effectiveness, Canada, January 2018. Euro Surveill. 2018;23(5):1800035. https://doi.org/10.2807/15607917.ES.2018.23.5.18-00035 PMID: 29409570

37. Instituto de Salud Carlos III (ISCIII). Informe Semanal del Sistema de Vigilancia de la Gripe en España (SVGE). [Weekly Report of the Influenza Surveillance System in Spain]. Week $17 / 2018$ (23 to 29 April). Published on 3 May 2018 (N. 543). Spanish. [Accessed 10 May 2018]. Available from: http:// vgripe.isciii.es/inicio.do

38. Public Health England (PHE). Weekly National Influenza Report. Week 18 report (up to week 17 data); 3 May 2018. [Accessed 10 May 2018]. Available from: https://assets.publishing.service. gov.uk/government/uploads/system/uploads/attachment_ data/file/704664/Weekly_national_influenza_report week_18_2018.pdf

39. The Francis Crick Institute. Reported prepared for the WHO annual consultation on the composition of influenza vaccine for the Northern Hemisphere 2018-2019. London: The Francis Crick Institute;2018. [Accessed 10 May 2018]. Available from: https://www.crick.ac.uk/media/409431/crick_feb2018_report for_the_web.pdf

40. World Health Organization (WHO). Recommended composition of influenza virus vaccines for use in the 2018-2019 northern hemisphere influenza season - full report. Geneva: WHO. [Accessed 19 Jun 2018]. Available from: http://www.who. int/influenza/vaccines/virus/recommendations/201802 recommendation.pdf?ua $=1$

41. Mosterín Höpping A, Fonville JM, Russell CA, James S, Smith DJ. Influenza B vaccine lineage selection--an optimized trivalent vaccine. Vaccine. 2016;34(13):1617-22. https://doi. org/10.1016/j.vaccine.2016.01.042 PMID: 26896685

42. van de Sandt CE, Dou Y, Vogelzang-van Trierum SE, Westgeest $\mathrm{KB}$, Pronk MR, Osterhaus ADME, et al. Influenza B virusspecific CD8+ T-lymphocytes strongly cross-react with viruses of the opposing influenza B lineage. J Gen Virol. 2015;96(8):2061-73. https://doi.org/10.1099/vir.0.000156 PMID: 25900135

43. Laurie KL, Horman W, Carolan LA, Chan KF, Layton D, Bean $A$, et al. Evidence for Viral Interference and Cross-reactive 
Protective Immunity Between Influenza B Virus Lineages. J

Infect Dis. 2018;217(4):548-59. https://doi.org/10.1093/infdis/

jix509 PMID: 29325138

44. Sullivan SG, Chilver MB, Carville KS, Deng YM, Grant KA,

Higgins $G$, et al. Low interim influenza vaccine effectiveness, Australia, 1 May to 24 September 2017. Euro Surveill.

2017;22(43):1700707. https://doi.org/10.2807/1560-7917.

ES.2017.22.43.17-00707 PMID: 29090681

45. Pebody R, Warburton F, Ellis J, Andrews N, Potts A, Cottrell $S$, et al. End-of-season influenza vaccine effectiveness in adults and children, United Kingdom, 2016/17. Euro Surveill. 2017;22(44):1700306. https://doi.org/10.2807/1560-7917. ES.2017.22.44.17-00306 PMID: 29113630

46. Ikonen N, Murtopuro S, Haveri A, Virtanen MJ, Baum U, Isoniemelä Y, et al. Influenssakausi Suomessa, viikot 40/201720/2018. Available from: http://www.julkari.fi/bitstream/ handle/10024/136791/URN_ISBN_978-952-343-159-1. pdf? sequence $=1$ \&isAllowe $\bar{d}=y$

47. Butler AM, Layton JB, Krueger WS, Kshirsagar AV, McGrath LJ. Assessing Residual Bias in Estimating Influenza Vaccine Effectiveness: Comparison of High-dose Versus Standard-dose Vaccines. Med Care. 2019;57(1):73-8. https://doi.org/10.1097/ MLR.0000000000001018 PMID: 30422840

48. Lund JL, Richardson DB, Stürmer T. The active comparator, new user study design in pharmacoepidemiology: historical foundations and contemporary application. Curr Epidemiol Rep. 2015;2(4):221-8. https://doi.org/10.1007/s40471-0150053-5 PMID: 26954351

49. Ellis PD. The essential guide to effect sizes: statistical power, meta-analysis, and the interpretation of research results. Cambridge; New York: Cambridge University Press; 2010.

\section{License, supplementary material and copyright}

This is an open-access article distributed under the terms of the Creative Commons Attribution (CC BY 4.0) Licence. You may share and adapt the material, but must give appropriate credit to the source, provide a link to the licence and indicate if changes were made.

Any supplementary material referenced in the article can be found in the online version.

This article is copyright of the authors or their affiliated institutions, 2019. 